\title{
3. El Cristianismo del futuro Según Teilhard de Chardin
}

Pese a la incontenible oleada de incredulidad moderna, Teilhard nunca pudo tomar en consideración la posibilidad de una futura humanidad sin cristianismo. A mayor consciencia y libertad corresponde en buena lógica un aumento correlativo de religiosidad. En el artículo precedente he dejado expuesto su diagnóstico sobre la crisis religiosa actual: se trata de una nueva forma de religiosidad, actualmente en conflicto con la antigua, que es lo que le confiere su apariencia de irreligiosidad.

Ya hemos visto también cómo la renovación del cristianismo que propone se apoya sobre esta tesis: el cambio de dimensiones introducido por los nuevos descubrimientos, especialmente por la evolución generalizada, obliga a una (trasposición" del contenido religioso evangélico a los nuevos parámetros dimensionales. Del éxito de esta operación depende no sólo el que la religión - componente humano estructural - pueda cumplir su función animadora y trascendente, sino que se juega en ella su propia supervivencia, pues la corriente humana de fondo no tardaría en desprenderse de un ingrediente entorpecedor y alienante.

Todo lo que sucede es que se ha manifestado ante nosotros una nueva (divinidad»: la super-humanidad que tenemos que construir. Es decir, hablando con mayor exactitud, sucede que la corriente religiosa natural se ha transformado espontáneamente ante los nuevos parámetros y perspectivas. Ya no se trata de mantener un orden y un equilibrio seculares, sino de avanzar (a la conquista de un nuevo Santo Grial)».

Esta corriente religiosa natural es hoy más poderosa que nunca, aunque la imagen de su (Dios) permanezca todavía bastante borrosa. Pero esta imagen se centra en el objetivo de una super-humanidad que hay que construir por imperativo estructural de la cosmogénesis en que navegamos. Es la religión de la Evolución, que ha tomado cuerpo en los nuevos humanismos. 
El Mundo se está convirtiendo espontáneamente a una "Religión natural del Universo), que le desvía del Dios evangélico. Pero este desvío no es estructural, sino circunstancial: acontece porque el Dios evangélico se continúa ofreciendo en unos moldes y en un cuadro de planteamientos histórico-culturales que resulta ya irrespirable para los hombres de nuestro tiempo. De aquí también la fuerte crisis interna que experimenta el cristianismo, en el conjunto de la crisis religiosa mundial. Teilhard no vacila un momento en su diagnóstico: es una crisis de metamorfosis y, por tanto, de crecimiento. Nunca como ahora ha estado presta la humanidad para recibir un Salvador.

Ahora bien, el espíritu religioso tradicional está recibiendo un aflujo brusco y masivo de nueva savia. De aquí que se agite y se transforme en su totalidad y en su misma trama. Ante esta situación, los "Credos religiosos", ya codificados en una época anterior, se resisten a variar su fisonomía, sin percatarse de la gravedad de su resistencia. Amenazan convertirse en "veladores) de Dios en lugar de ser sus (reveladores). Porque lo cierto es que sus (dogmáticas) y sus (morales) no reflejan ya la relación religiosa "tal como Dios se le presenta al hombre de hoy"s.

Mientras no se realice la trasposición de su mensaje eterno a una imagen de Dios que el hombre moderno pueda (adorar), seguiremos asistiendo a una subida incontenible del ateísmo, paralela a la simultánea descristianización. Se ha producido un malentendido fundamental: el Dios "Hacia-Adelante) choca con el Dios "Hacia-Arriba). y en este malentendido se halla el corazón del problema). Porque no se apoya en razón estructural alguna. Precisamente, ambos movimientos se postulan mutuamente para realizarse de un modo pleno y satisfactorio.

Urge, ante todo, desprender al cristianismo -(filum) religioso central- de las apariencias o añadidos histórico-culturales que le confieren un aspecto (inhumano») e (inferior). Tanto más cuanto que con ello no sólo recupera todo su poder de sugestión - por el que se vehiculiza su mensaje sino que consigue recobrar virtualidades propias olvidadas, al mismo tiempo que se produce un desarrollo magnífico de su contenido doctrinal: la cosmogénesis le permite formular una Cristología verdaderamente cósmica, que le convierte de hecho en (la) religión de la humanidad, incluídas sus dimensiones ex- 
tra - y sobre - terrestres. En su cauce se recoge espontáneamente la mejor savia de las grandes religiones de la tierra (ecumenismo de base $y$ de convergencia).

Acabo de exponer en los capítulos precedentes las líneas directrices y algunos desarrollos concretos de la solución traspositiva de Teilhard. Pero todavía no hemos agotado el provecto teilhardiano. Nos falta considerar su aspecto más decisivo $y$, posiblemente, más revolucionario. Aunque también haya sido el más silenciado o minimizado por los comentadores de Teilhard. Me refiero a sus perspectivas para el cristianismo del futuro en el marco del ecumenismo integral humano-religioso-cristiano.

Para ello me apoyaré, principalmente, en un ensayo verdaderamente genial, lleno de originalidad y valentía: Cómo creo yo ${ }^{1}$. A primera vista parece tratarse de un testimonio psicológico personal con vistas a una finalidad apologética; esto es, analizar y describir las razones, los matices, las etapas, los límites y las dificultades que había experimentado su fe cristiana individual. Se sitúa, pues, como tantas veces, al menos inicialmente, en el ámbito de la psicología religiosa. Pero sería miopía considerarlo en el género de los testimonios de convertidos. A mi entender, se acerca mucho más al modelo agustiniano de las "Confesiones), en el que las vicisitudes individuales alcanzan dimensiones estructurales, paradigmáticas.

Por eso me parece inadmisible reducirlo a una intención apologético-metodológica para los no-creyentes (H. de Lubac), o una ( ria interior» (G. Crespy); ni que se trate, primariamente, de unir la (fe en el Mundo) con la ("verdad científica) (J. P. Demoulin) ${ }^{2}$.

Como Agustín de Hipona, Teilhard de Chardín piensa que su ca-

1. Escrito en 1934, a petición expresa de Bruno de Solages, Rector del Instituto Católico de Toulouse. El mismo Teilhard lo consideraba como intento de una nueva "Summa ad Gentes". Esto ha provocado ciertos malentendidos entre los comentadores, como expongo más adelante.

2. H. de Lubac, "Nota sobre la apologética teilhardiana", en La oración de TC, 155-223. Hay que tener en cuenta, no obstante, que de Lubac se propone defender a Teilhard de los ataques integristas (Garrigou-Lagrange, Ph. de la Trinité, G. Frénaud). Se apoya en Leys y Crespy quienes, en realidad, van mucho más lejos que él. Esto no obsta para que la interpretación de H. de Lubac sea la más socorrida, por su innegable prestigio y también por ser la menos comprometedora. A mi entender, con ella se desvirtúa totalmente el intento de Teilhard. G. Crespy (EI pensamiento teológico de TC, 79-89) ha visto claramente el proyecto teilhardiano, pero no se atreve a aceptarlo más que como un " ensayo de navegación". Finalmente, J.-P. Demoulin ("Etudes teilhardienes, I, 1968, 107-142) lo dese:Ifoca al plantearlo en el contexto de la ciencia y la fe, en conexión con El fenómeno humano. 
so es (significativo». Y lo es por idéntica razón situacional: ambos se apoyan en su experiencia personal para ofrecer una trasposición del cristianismo a la nueva edad histórica-cultural. $\mathrm{Y}$ es claro que ambos pasan del orden individual al colectivo. Porque - decía Agustín"¿qué es mi corazón sino un corazón humano?». Mientras que Teilhard no duda en afirmar: (eel Hombre es esencialmente el mismo en todos; basta descender a suficiente profundidad en sí mismo para encontrar un fondo común de aspiraciones y de luz. Por emplear una fórmula por la que ya transita mi tema fundamental: (alcanzamos lo Universal a través de lo que poseemos de más incomunicablemente personal ${ }^{3}$.

En efecto, Cómo creo yo -esas "Confesiones del siglo veinte»registran y proponen la originalidad de la creencia cristiana a partir de una situación individual que se ha hecho ya común en los cristianos de nuestro tiempo y que lo será todavía más en un futuro próximo: la conjunción de las aspiraciones ascensionales (trascendentes) con las progresivas (inmanentes). Dos aspiraciones que todavía hoy son consideradas mayoritariamente como antagónicas, pero que la experiencia de Teilhard demuestra no sólo armonizables, sino mutuamente implicadas y potenciadoras. Tanto que no es posible realizar plenamente una de ellas sin incorporar simultáneamente la otra. La fe en Dios pasa por la fe en el mundo y en el hombre. Y viciversa : el hombre y el mundo sólo se consuman en Dios. Esta es la gran revolución para el cristianismo del futuro.

Por lo demás, el planteamiento del propio Teilhard no deja lugar a dudas. Se propone ofrecer una memoria "confesional», en el marco de "la psicología religiosa). Trata de fijar, "a título documental», (las razones, los matices, y también los límites o Tas dificultades de mi fe cristiana). Advierte - por modestia obvia - que no lo hace porque (me tengo por mejor o más importante que cualquier otro». Lo que ocurre es que, "por una serie de razones accidentales, mi caso es significativo, y por este título merece ser registrado».

$Y$ expone a continuación (la originalidad) de su creencia cristiana : "tiene sus raíces en unos ámbitos de vida habitualmente considerados como antagonistas) :

3. CYP, 106/ $x, 118 /$. 
"Por educación y por formación intelectual, pertenezco a los 'hijos del Cielo'. Pero por temperamento y por estudios profesionales soy un 'hijo de la Tierra'. Colocado así por la vida en il corazón de dos mundos cuya teoria, lengua y sentimientos conozco por una experiencia familiar, no he tenido que levantar ningún tabique interior entre ellos. Por el contrario, he dejado que reaccionaran con plena libertad una sobre otra, en el fondo de mí mismo, dos influencias aparentemente contrarias. $Y$, al término de esta operación, después de treinta años consagrados a la consecución de esta unidad interior, tengo la impresión de que se ha logrado una síntesis, de la manera más natural, entre las dos corrientes que me solicitan. Ninguna de las dos ha matado a la otra, sino que la ha reforzado. Hoy creo probablemente más que nunca en Dios, y ciertamente más que nunca en el Mundo. ¿No está aquí, a escala individual, la solución particular, al menos esbozada, del gran problema espiritual con el que tropieza, hoy día, el frente avanzado de la humanidad?" ${ }^{4}$.

En este interrogante se encuentra la clave del ensayo. No obstante, Teilhard adopta una postura de lógica modestia. Asegura que (no pretende, en manera alguna, fijar la teoría de una apologética general). Quiere mantenerse en los límites de una (experiencia personal). Ya sabe que no va a gustar a todos: (a uno o a otro de mis lectores les parecerá discutible esta o aquella evidencia mía). Por eso se limita "a lanzar al viento la semilla).

Pero inmediatamente deja entrever la universalidad de su proyecto: "a fin de cuentas, y bajo expresiones de formas infinitamente variadas, no puede haber más que un eje de progresión espiritual hacia Dios. Aun cuando se hallen expresadas en términos completamente subjetivos, muchas de las cosas que voy a decir tienen necesariamente sus equivalentes en temperamentos diferentes del mio $y$, por simpatia, habrán de hacerlos resonar. El Hombre es esencialmente el mismo en todos (...) ) ${ }^{5}$.

Pero es que, además, este ensayo forma parte de toda una cadena de escritos teilhardianos, que se remonta a $L a$ vida cósmica, se continúa por los dos Mi Universo, desemboca en El corazón de la Materia y culmina en Lo Cristico, por citar solamente los más relevantes $^{6}$.

\footnotetext{
4. lb., 105-6/ $x, 117-8 /$.

5. lb., 106/ $x, 118 /$.

6. He aqui el testimonio rigurosamente paralelo de Mi Universo (1924): "Me propongo simplemente exponer aqui la manera personal de comprender el Mundo (...) por un proceso (...) aportar un testimonio psicológico irrefutable (...) un hombre medio del siglo veinte, en la medi-
} 
Baste recordar solamente el testimonio del último escrito mencionado. Ya en 1955 podía registrar Teilhard cómo se difundía (en el seno de la nueva atmósfera espiritual creada por la aparición de la idea de Evolución, en un estado de sensibilización mutua extrema, el amor de Dios y la fe en el Mundo: los dos componentes esenciales del Ultrahumano". Y precisaba: estos dos elementos se encuentran (en el aire» por todas partes. Pero generalmente no son lo suficientemente fuertes "los dos a la vez, para combinarse mutuamente en el mismo sujeto».

Piensa que su caso fue excepcional, aunque por puro azar, ya que tanto por temperamento como por medio ambiente y educación, consiguió la justa proporción para que se realizase espontáneamente la (fusión) de ambos componentes. Pero esta síntesis ha sido demasiado débil para propagarse (explosivamente). Sin embargo, sí ha sido lo suficientemente expresiva para demostrar que «la reacción es posible». Y añade con acento profético: ellos nos garantizan que «un día $u$ otro, la cadena se establecerán, pues basta que la verdad aparezca en un solo espíritu para que ya lo invada y lo inflame todo, irresistiblemente ?

da en que participaban normalmente en las ideas y en las preocupaciones de su tiempo, sólo ha podido encontrar el equilibrio de su vida interior en una concepción fisicista y unitaria del Mundo $y$ de Cristo. $Y$ que ha encontrado alli una paz y una expansión sin límites.

"(...) una tendencia espiritual ha intentado tomar cuerpo en mí. Una tendencia que, después, otros advertirán más afortunadamente que yo. Siento verdaderamente que no soy yo quien ha concebido estas páginas, sino, dentro de mí, un Hombre más grande que yo, un Hombre al que he reconocido, siempre el mismo, cien veces a mi alrededor.

"Porque el destino me ha colocado en un cruce privilegiado del Mundo en el que, en mi doble calidad de sacerdote y de hombre de ciencia, he podido sentir pasar a través mío, en condiciones particularmente exaltantes y variadas, la doble oleada de las potencias humanas y divinas; porque en esta situación de elegir en la frontera de dos mundos, he encontrado amigos excepcionales para abrir mi pensamiento y ocios prolongados para madurarlo y fijarlo; pienso que sería infiel a la Vida, infiel también a los que necesitan que les ayude (...), si no intentara transmitirles los lineamientos de la espléndida figura que se ha descubierto ante mi en el Unt. verso durante veinticinco años de reflexiones y de experiencias de toda clase.

"Lo que da al punto de vista que voy a procurar definir su poder de seducción y su valor de paz, es la manera flexible y fácil en que, a partir de él, se encadenan, se ordenan, se esclarecen mutuamente -hasta donde la vista no alcanza, y en su fondo más intimo- los innumerables elementos del mundo físico, moral, social, religioso... Toda mi 'apologética' consistirá en mostrar esta coherencia sólida, natural, total". CC, 59-61/ IX, 65-7/.

En 1919, al frente de su Nota para la evangelización de los tlempos nuevos escribía: “...) he aquí lo que quiero decir, porque lo he sentldo" ETG, 367.

Igualmente, al comenzar Lo Crístico (1955): "Estas páginas representan un testimonio ofrecido, con toda objetividad, sobre un acontecimiento interior, sobre una experiencia personal, en los que me resulta imposible no discernir los signos de una deriva general de lo Humano sobre sí mismo". Prólogo (inédito).

7. Lo Crístico, conclusión (inédito). En realidad, este opúsculo es un replanteamiento del mismo tema de Cómo creo yo. Del mismo modo, El Cristianismo en el mundo (1933) es un primer intento, como Bosquejo de una dialéctica del espiritu (1946) es un desarrollo paralelo, en busca de una explicitación dialéctica, como advierte el mismo Teilhard: 
Pero, ¿cuáles son los factores estructurales de esta experiencia cristiana renovada? Es lo que Teilhard se propuso descubrir y describir en Cómo creo yo, de forma explicitada y sistemática. Lo que, dado su planteamiento confesional-universal, según acabo de exponer, lo convierte en un documento fundamental a la hora de precisar el pensamiento teilhardiano.

Esta visión del cristianismo futuro puede resumirse en cinco pro. posiciones centrales:

a) carácter dialéctico-evolutivo de la fe cristiana;

b) la fe en Dios nace de la fe en el Mundo (en el Hombre);

c) un ecumenismo de base (convergencia de las religiones en un "credo» común);

e) (Las sombras de la fe»)».

d) La religión del Cristo-Universal;

a) Carácter dialéctico-evolutivo de la fe cristiana.

Amparándose en su planteamiento desde la psicología religiosa, subraya Teilhard la estructura dialéctico-evolutiva de la fe cristiana, según un postulado primordial: «toda fe nace de una fe». De este modo, la fe cristiana va a revelársenos como un despliegue, en cuatro etapas sucesivas, que van de lo primario a lo explicitado, de lo estructural a lo dialéctico-evolutivo, siempre a partir de un acto de fe básico, primordial. Se trata de un enfoque psicológico, pero bien sabemos que detrás de toda psicología se esconde una ontología (en este caso, una teología).

Pero es preciso comenzar por fijar una noción, aunque sea genérica, de lo que significa ( $f e$ ). En este sentido no duda en afirmar: (entiendo por fe toda adhesión de nuestra inteligencia a una perspectiva general del universo». En efecto, detrás de toda cosmovisión se descubre una fe más o menos explicitada. Esta (adhesión) se ha definido por los aspectos de libertad ((copción)) o de afectividad ((atracción») que la acompañan. A Teilhard esto le parece ya (derivado o

\footnotetext{
“Por no haber observado suficientemente esta ley de alternancia, claramente indicada, sin embargo, en mis escritos, sobre todo en (Cómo creo yo), ciertos lectores han creido advertir 'panteismo' o 'naturalismo' en los diversos ensayos en los que me he esforzado por fijar la acción del hombre moderno en su búsqueda de Dios. A fin de evitar todo equívoco en lo sucesivo, me parece útil presentar aquí, claramente desarticulados, los tiempos sucesivos de mi apologética 0 , si se prefiere, de mi dialéctica". AE, 139/ VII, 149/.
} 
secundario». Lo esencial le parece la percepción y la aceptación de una conclusión que (desborda todas las premisas analíticas». Es decir, le parece primordial su carácter "utópico». Por eso arriesga decididamente esta definición: "Creer es efectuar una sintesis intelectual)s.

Ahora bien, establecida esta noción genérica de fe, es ineludible aceptar (la condición primera que nuestra experiencia impone a cualquier objeto para ser real)): su estructura evolutiva. De tal modo que ni se mantiene "siempre idéntico a sí mismo, ni por el contrario, cambie sin cesar, sino que crezca sin perder ciertas dimensiones propias que le hacen seguir siendo continuamente homogéneo a sí mismo".

$\mathrm{Y}$ aclara seguidamente el alcance de esta afirmación: todo nace y se desarrolla según la ley de la discontinuidad en la continuidad. Por eso, "toda vida nace de otra vida, o de una pre-vida) y, similarmente, "toda libertad de otra libertad o pre-libertad». Lo mismo acontece en el terreno de las creencias: "toda fe nace de una fe", esto es, de otra $\mathrm{fe}$ antecedente. Se trata siempre de un desarrollo dialéctico-evolutivo: como la libertad asciende al captar y construir determinismos, así la fe "progresa en nuestros espíritus tejiendo en torno a sí una red coherente de pensamientos y de acción).

Pero no podemos olvidar que dicho proceso ha sido posible a partir de una base primaria, de un acto de fe fundamental: (esta red no se despliega ni se sostiene, en definitiva, sino bajo la influencia organizadora de la fe inicial». En psicología religiosa se descubre traspuesto el mismo (principio de homogeneidad que domina todas las transformaciones sintéticas de la Naturaleza». Por eso podemos completar ya la noción genérica de fe: "Creer es desarrollar un acto de sintesis cuyo origen primero es inaprensible».

Por eso, la fe cristiana explicitada ha de nacer, crecer y desplegarse - según una evolución psicológica estructural, aunque admita variantes- a partir de (creencias cada vez más elementales, hasta llegar a una cierta intuición fundamental bajo la cual no discierno ya nada). Es preciso, pues, descender hasta la creencia básica, primordial, a partir de la cual se desarrolla, a la manera de un (filum» biológico, una serie de actos de fe sucesivos, según los umbrales recurrentes dialécticamente implicados.

Al final encuentra que la cosmovisión explicitada «acaba por 
coincidir con el cristianismo». Por eso se marca decididamente el pro. grama a seguir:

"Verificar ante todo, la solidez de una fe inicial inevitable. Verificar luego la continuidad orgánica de los estadios sucesivos atravesados por el crecimiento de esta fe".

Y asegura con cierta solemnidad: (no conozco para mí mismo otra apologética. $Y$, además, no sabría sugerir ninguna otra a aquéllos a quienes les deseo la suprema dicha de encontrarse un día cara a cara con un Universo unificado) ${ }^{8}$.

\section{b) La fe en Dios nace de la fe en el Mundo (en el Hombre).}

Esa fe inicial, esta (adhesión fundamental), la descubre Teilhard en (la fe en el Mundo). Y se trata de una creencia tan básica que, aunque sucediese (algún derrumbamiento interior» por el que (llegara yo a perder sucesivamente $\mathrm{mi}$ fe en Cristo, $\mathrm{mi}$ fe en Dios personal, mi fe en el Espíritu, me parece que seguiría invenciblemente creyendo en el Mundo». Esto es, seguiría creyendo en (cel valor, la infalibilidad y la bondad del Mundo». Y lo confirma a continuación : "tal es, en último análisis, la primera, la última y la única cosa en la que creo. Vivo para esa fe. Y yo sé que, en el momento de la muerte, me abandonaré a esta fe, por encima de todas las dudas» ?

Una afirmación tan grave nos conduce a esta pregunta: ¿de qué "Mundo» se trata? Evidentemente, se trata del Mundo que se despliega en una cosmo-bio-antropogénesis convergente, tal como se expresa en el frontispicio del ensayo:

\footnotetext{
8. CYC, 107-8/ X, 119-120/. Cfr. nota precedente.

Su correspondencia confirma esta opinión: "Observe la curiosa apologética a la que me siento empujado. Las 'visibilia' —cosas visibles - para mí no son solamente una premisa lógica para el razonamiento que conduce a las Invisibles. Cnstituyen para mi un primer mundo de fe, del cual el Mundo de la $\mathrm{Fe}$ sobrenatural no es más que el desarrollo. Me pregunto si esa apologética no es la única legítima. Una fe no puede nacer más que de una fe (y no de un razonamiento): si no, el proceso no sería homogéneo. Las operaciones espirituales deben ser homogéneas (como se diria en matemáticas). Es uno de los aspectos fundamentales de la ley de la evolución". Carta a A. Valensin, 25/II/1929, citada por J./P. Demoulin, loc. cit., 111-2. Obsérvese la nitidez con que expone su posición. El segundo subrayado es mío. Cfr. tb. CV, 185-6/ LV,

9. CYC, 109/ X, 120/. Esta afirmación ha sido malentendida con frecuencia. Para los teólogos integristas es una confesión de naturalismo flagrante. $H$. de Lubac ha defendido a Teilhard apelando a su carácter de texto apologético. Sería simple cuestión de "táctica". Apela también a la "analogia" teilhardiana. Pero el texto citado en nota precedente basta para desmentir tal interpretación "domesticadora".

No obstante, es cierto también que el propio Teilhard pareció intimidarse un tanto al recibir
} $178-9 \%$. 
"Creo que el Universo es una Evolución.

Creo que la evolución va hacia el Espíritu.

Creo que el Espíritu, en el Hombre, culmina en lo Personal.

Creo que lo Personal supremo es el Cristo-Universal» ${ }^{10}$

Es éste un viejo - y fundamental - tema teilhardiano, que ya aparece nítido en los escritos de su primera época. En la Vida cósmica (rgi6) tenemos este texto rigurosamente paralelo:

"¡La Vida! ¿A dónde acudiríamos en ciertas horas de extrema turbación sino al último criterio, a la suprema decisión de su logro y de sus caminos? Cuando vacilan todas las certidumbres, balbucean todas las palabras, se vuelven sospechosos todos los principios, ¿a qué última creencia asir nuestra existencia interior a la deriva sino a ésta: que existe un sentido absoluto de crecimiento (...) (...) hay para mí una convicción infinitamente dulce y tenaz, profunda y querida; la más humilde, pero también la más fundamental en todo el edificio de mis certidumbres : la Vida no engaña(...) hay un más-ser, un mejor-ser absolutos que se llaman progreso en la conciencia, la !ibertad, la moralidad ${ }^{11}$.

La noción de "Vida) se corresponde manifiestamente con la de "Mundo», utilizada en Cómo creo yo. Más exactamente, coincide con la creencia fontal, primaria, que se desplegará en cuatro tiempos o etapas: fe en el Mundo, fe en el Espíritu, fe en la inmortalidad, fe en la Personalidad.

\section{La fe en el mundo:}

En definitiva, comprobamos que la fe inicial, la creencia básica, la adhesión fundamental es un acto de fe en el ser: "Lógica y psicológicamente, el primero de estos principios es la convicción profunda de que el ser es bueno, es decir, a) que es preferible ser que no ser; b) que es preferible ser más que ser menos». Sobre esta creencia bá-

\footnotetext{
la brutal crítica de Garrigou-Lagrange, a la que contesta de este modo: "En esta Nota -cómo creo yo-, destinada, por otra parte, a un público determinado y no al gran público, describo exclusivamente unos pasos psicológicos, en el orden de los motivos de credibilidad (esfuerzo por encontrar a Dios por medio de la razón: primer tiempo del Concilio Vaticano. En esta fase preliminar, subyacente en la adhesión sobrenatural a lo revelado, el acto de fe teológico no es negado,puesto que no ha entrado todavia en consideración". (Escrito de 1947, citado por H. de Lubac, loc. cit., 208).

10. CYC, $105 / \mathrm{X}, 117 /$.

11. ETG, 43-4/ 22-3/. Es sintomático que ninguno de los comentaristas de este tema teilhardiano haya reparado, que yo sepa, en esta manifiesta anticipación.
} 
sica se apoyan los principios fundamentales: primacía de la conciencia, fe en la vida, fe en lo absoluto, prioridad del todo ${ }^{12}$.

Naturalmente, en esta fe inicial en el ser, en la vida, en el mundo, late toda una filosofía de la acción, como ilustra con bastante claridad el ensayo acción y actividad (1945). Para la filosofía moderna, (ser) no es ya sinónimo de ((conocer), sino de ("crecer), (devenir»). Existe un equilibrio ontológico entre lo inteligible, lo actuable y lo activante, es decir, entre la realidad y las más profundas aspiraciones humanas. De ahí que pueda formularse el principio del (Máximo": "lo que nuestra razón y nuestro corazón exigen esencial y positivamente para estar satisfechos, lo posee el Mundo»; esto es, (lo más inteligible y lo más activante es necesariamente lo más real y verdadero». De donde se deduce que, para satisfacer (el principio de activancia máxima», el Mundo ha de cumplir tres condiciones generales: ser ((abierto», (irreversible) y poseer un (valor) absoluto» ${ }^{13}$

Ahora comprendemos mejor la frase (escandalosa): (El Mundo (el valor, la infalibilidad y la bondad del Mundo), tal es, en último análisis, la primera, la última y la única cosa en la que creo). No hay por qué recurrir a un artificio de "táctica) o "ficción". Tanto menos cuanto que la noción de (Mundo» incluye, además de la fe inicial en el ser, (cuna adhesión completa a lo que se desarrolla en torno a nosotros, y en nosotros, en el Universo") ". Luego se comprueba que su despliegue se corresponde con el cristianismo.

En su fase incoativa, esta fe en el Mundo se manifiesta, primordialmente, por un agudo sentido de las interdependencias

\footnotetext{
12. En su segundo Mi Universo (1924) habia desglosado de este modo los componentes de la fe en el Mundo:

1) Primacía de la conciencia (a más conciencia, más ser);

2) Fe en la Vida (en su conjunto, tiene un fin que no puede frustrarse. Sea cual fuere su causa - providencia trascendente, Omega inmanente, infalibilidad de los grandes números o los tres factores combinados-, lo seguro es que el Mundo no fallará, ahora que se ha hecho consciente en el Hombre, y ha superado ya las mayores improbabilidades);

3) Fe en lo Absoluto (las adquisiciones del Mundo son definitivas, irreversibles. Si el Mundo está bien construido $-y$ todo parece indicarlo así-, no puede ser contradictorio);

4) Prioridad del Todo (el Mundo se me revela como una inmensa interligazón orgánica en origen, estructura y destino. Es una intuición más que una inferencia: "nada es comprensible en el Mundo más que a partir del Todo, en el Todo"). CC, 61-6/ IX, 67-72/.

Nótese la filosofía de la acción, subyacente en tales principlos.

13. CC, 201-5/ X, 221-5/. Como es obvio, he de limitarme a señalar el tema.

14. Carta a Gaudefroy, 14/11/1935, citada por J.F., Demoulin, loc. cit., 114.

En 1955 confirmaba esta noción de "Mundo": "el inmenso proceso cósmico de ordenación cuya presencia revoluciona, para quien sabe ver, la totalidad de nuestro conocimiento". Carta fechada el 14/1/1955, citada por R. d'Ouince, op. cit., I, 186.
} 
universales. Es la actitud "mística" frente a la "dualista". Es el pensamiento moderno que descubre el carácter dialéctico-evolutivo de la epistemología, la biología, la física... Es la organicidad del todo, de la que se sigue una interdependencia del mismo orden, en el nuevo parámetro espacio-temporal, que es ya una condición general de conocimiento y acción. De momento importa subrayar este carácter de "totalidad". Luego veremos su forma concreta, estática o dinámica, material o espiritual, progresiva, periódica o circular.

En esta misma constatación chocan ya dos texituras mentales, (dos clases de espíritus». Desde la investigación científica a las preocupaciones sociales y religiosas, se encuentran dos (actitudes» profundamente antagonistas, sin posibles puentes entre ambas: los (pluralistas) y los (monistas). Los primeros no trascienden -ni sienten la necesidad de trascender- la percepción directa de lo múltiple fenoménico; en cambio los segundos la superan espontáneamente para descubrir su unidad estructural. Son "los que no ven" v "los que ven». Dos tendencias congénitas, quizá irreformables.

Y no vale decir que son cuestiones de (gusto") o de (temperamento). Esto no es una solución, sino una evasiva. Existe la misma diferencia que se da entre lo (negativo» y lo (positivo». Los pluralistas (no ven"); los (monistas (ven). Pero a quien no ve es imposible hecerle ver. Se trata de una intuición primaria o, mejor, de un apriori cognoscitivo, un "sentido especial), en virtud misma de su "ser en el Mundo). Es el (sentido cósmico», nueva adquisición evolutiva, que no ha llegado aún a todos. En los pluralistas cel sentido del Todo) duerme todavía. Pero no son más que monistas que se ignoran ${ }^{15}$.

\section{La fe en el Espiritu:}

La fe confusa en un Mundo Uno e Infalible, a la que nos hemos confiado donde quiera que nos lleve comienza a precisar sus contornos mediante sucesivos tanteos. Aquí intervienen decisivamente los factores educacionales y personales.

Un primer punto se hace manifiesto: el Mundo posee una es-

\footnotetext{
15. CYC, 110-3/ X, 120-4/.

La mencionada carta a Gaudefroy contiene una explicitación de esta idea: "-los investigadores - se dan, instintivamente, a algo que adoran. No se da la vida por un crucigrama. (...) Lo que nosotros reconocemos profundamente verdadero en nosotros mismos debe existir y ser verdadero en los otros". Cit. ib., 116-7.
} 
tructura dinámica o evolutiva. Es la revelación de la Duración, que enebra la totalidad de los seres en las fibras de un proceso universal: "Cada ser se hace coextensivo, por su historia, con la Duración entera y su ontogénesis no es más que el elemento infinitisimal de una Cosmogénesis».

Así, pues, el mundo se nueve. Pero, chacia dónde lo lleva este movimiento? Teilhard responde como "historiador de la vida" (paleontólogo) tanto como (filósofo", desde el fondo de su inteligencia y de su corazón: "Hacia el Espíritu».

Se trata, pues, de una evolución espiritual. Todavía hoy, por efecto de la (ilusión analítica» tan generalizada, que confiere más realidad a los elementos del análisis que al término de la síntesis, se piensa que la evolución es forzosamente materialista. Pero una fenomenología integral (“sólo el fenómeno, pero todo el fenómeno») nos descubre que la materia y el espíritu constituyen una unidad genética y dinámica inseparable, que sigue la ley de complejidad-conciencia.

el hombre creador de toda ciencia, no haya encontrado todavía su puesto como fenómeno natural. La inteligencia, y cuanto tiene de

El caso del hombre es una buena muestra. Resulta asombroso que más humano, se presenta siempre como (inexplicable anomalía»... Esta antinomia debiera bastar para advertirnos sobre lo equivocado de nuestros planteamientos. Acostumbramos a partir de lo inferior para llegar a lo superior. Así nos exponemos a no comprender nunca lo superior, que representa una realidad mucho más rica y compleja. Debe intentarse, pues construir una Física (a partir del Espíritu).

Con este simple cambio de variable nos encontramos con que toda la vida terrestre adquiere una figura de coherencia siguiendo el eje de ascensión continua hacia más espontaneidad y conciencia. $Y$ en $l_{0}$ más alto del eje de complejidad-conciencia, el Hombre, centro axial de la evolución y (clave de la Tierra). Ahora es cuando comprendemos adecuadamente el sentido de los infinitos tanteos de la vida, su esfuerzo siempre ascendente hacia la tele-libertad y tele-conciencia, que triunfan, finalmente, en el Hombre.

No nos dejemos impresionar por la "ilusión de la Cantidad" ni de la (Fragilidad». El hombre puede representar una porción mínima del cosmos y parecer sumamente frágil. Pero la vida misma es el triunfo constante de la improbabilidad. Nos hallamos, pues, en el eje 
de la significación. Tampoco se nos acuse de (antropocentrismo» porque no existe más pensamiento que el pensamiento humano. ¿Es culpa nuestra (si coincidimos con el eje de las cosas)? ${ }^{16}$.

De todo lo cual podemos extraer las siguientes conclusiones:

- la Unidad del Mundo se presenta a nuestra experiencia como una subida de conjunto de la Conciencia hacia estados más espiritualizados.

-no se aprecia ningún antagonismo Materia-Espíritu; al contrario, el Espíritu "nace en el seno y en función de la Materia" (conciencia en función de Complejidad).

- la dirección del Cosmos y del Hombre no es otra que hacia una mayor conciencia. De aquí su pasión de ser-más, de engrandecerse ${ }^{17}$.

\section{La fe en la Inmortalidad:}

Con el descubrimiento de que "la evolución va hacia el Espíritu) parece que lo hemos descubierto ya todo. Pero pronto comprendemos que de poco serviría esa espiritualización progresiva si el Espíritu no es irreversible, es decir, (inmortal). Ahora bien, para verificarlo, basta estudiar la naturaleza misma del Espíritu, que se nos ofrece como una magnitud en constante crecimiento y sin limitaciones intrínsecas (conocimiento y amor). La historia de la vida nos muestra que avanza sin retroceso. Esta es la mejor garantía de que así sucederá en el futuro, especialmente en un cosmos cuya ley fundamental parece ser: (todo lo posible se realiza) ${ }^{18}$ Las dos derivas cósmicas antagonistas, Entropía y Vida, son igualmente irreversibles.

\footnotetext{
16. CYC, 113-6/ X, 124-7/. Como puede observarse Teilhard se sitúa de lleno en la corriente "inobjetiva", "superobjetiva" o "espiritualista", que busca la fuente de la significatividad en los estratos superiores de la vida, en el espiritu, alli donde la realidad es más rica y más densa. Teilhard añade, además, su evolución generalizada. En un mundo evolutivo se comprende mejor cómo los seres superiores (en complejidad-conciencia, esto es, en espiritu) nos ayudan a comprender a los inferiores, según el principio de discontinuidad en la continuidad. El camino inverso, en cambio, es mucho más problemático, dada la creatividad de la vida.

17. CYC, 117-8/ X, 128-9/. En Mi Universo (1924), el primero de sus principios "fundamentales" lo formula asi: "la primacía de la conciencia". Cfr. nota 12.

El tema de las relaciones Espíritu-Materia to he tocado ya varias veces. Baste esta referencia: "El verdadero nombre del 'espíritu' es 'espiritualización' (...) Es un cambio de estado cósmico". EH, 105/ VI,121/.

18. CYC, 118-9/ X, 129-130/. Por supuesto, no se trata de un progreso lineal. Teilhard habla expresamente de un progreso "en conjunto" y cita un ejemplo concreto: el impresionante aumento de "las potencias colectivas del espíritu (sentido social) durante los dos últimos siglos.
} 
La filosofía de la Acción nos lleva a idéntico resultado. Efectivamente, actuar parece una función elemental. Pero, en realidad, precisa también su "Crítica». ¿Qué propiedades estructurales debe tener lo real para desencadenar el movimiento voluntario? ¿Qué condiciones debe satisfacer el Mundo para que nuestra libertad consciente se decida a intervenir? Con Blondel y Le Roy descubrimos la necesidad del "atractivo de un resultado indestructible), (una conquista inmortal). Luego existe ese Inmortal ante nosotros. Como decía Tucídides, cuando realizamos una acción verdaderamente humana intentamos hacer "una obra para siempre». Y no es la "vanidad de la posteridad", sino un instinto esencial: es lo único que nos hace interesar de verdad, aunque este (instinto) se muestre más en unos que en otros (problema de educación y de perspectivas). Pero la perspectiva de (una muerte total») paralizaría automáticamente todo esfuerzo.

Es más, llegará pronto el día en que la Humanidad, cen virtud de su misma posición en una Evolución cósmica que ha sido capaz de descubrir y criticar, se encuentra biológicamente emplazada entre el suicidio y la adoración). Por eso, será la Religión quien, finalmente, alimentará nuestra energía de auto-evolución. La existencia de una Inmortalidad es algo más que un deseo de supervivir : es una exigencia estructural. Si el Mundo, en su conjunto, es infalible y asciende hacia el espíritu, ello implica que el mundo no se sostiene "por abajo", sino (por arriba). Llegado a un estadio evolutivo consciente - $y$ por tanto, crítico- de auto-evolución, la exigencia de Inmortalidad -irreversibilidad total - se impone absolutamente, para que la Evolución no fracase al paralizarse nuestra Acción ${ }^{19}$.

\section{La fe en la Personalidad:}

He aquí cómo a partir de la fe inicial en el Mundo se ha hecho explícita la fe en una espiritualización creciente e indestructuble del mismo. Pero, ¿bajo qué forma podemos representar ese ctérmino inmortal») de la cosmogénesis? La casi totalidad de los monismos $1_{d}$ conciben como una potencia impersonal, en la que se ahogan nuestras personalidades. Sin embargo, ¿es ésta la solución correcta?

19. Ib., 120-3/ X, 131-3/. En otro estudio paralelo, en El fenómeno espiritual, deduce Teilhard las propiedades estructurales del mismo; irresistible, irreversible y totalizador, a la vez que postula directamente un fin personal. EH, 105-8/ VI, 122-5/. 
Teilhard piensa que dicha concepción arranca de una (ilusión espacial». En efecto, para nuestra experiencia, lo personal es un atributo exclusivo de lo particular en cuanto tal. Lo personal se vincula siempre a lo individual. En cambio lo universal lo concebimos siempre como algo vago, impersonal y absorbente. Nos parece mostruoso pensar por un momento en la hipótesis de un universal-personal, o una personalidad universal.

Lo que sucede es que, una vez más, somos víctimas de un planteamiento equivocado: pretendemos conocer lo superior a partir de lo inferior. De ahí nuestra "ilusión espacial", ya que en el mundo inferior al hombre no se constatan tales realidades. Pero, ¿constituye alguna prueba concluyente, sobre todo en un universo evolutivo? Precisamente, el estudio atento de la estructura de la evolución nos facilitará la solución adecuada.

Hemos visto cómo el universo es una evolución que asciende hacia el espíritu irreversiblemente, siguiendo un eje: la ley recurrente de complejidad-conciencia. La cosmogénesis se nos manifiesta como "Centrogénesis", al modo de esferas a partir de las cuales se constituyen nuevas esferas de superior centro-complejidad. Pero, justamente, la personalidad se caracteriza por su condición de "centro" incomunicable. Ello quiere decir que la estructura misma de la evolución es de naturaleza personal ${ }^{20}$.

Pero si la estructura misma de la evolución es personal, ello implica que debe llevarnos a un resultado de naturaleza personal. El hecho de que la evolución nos lleve ahora por caminos de socialización hacia una Super-humanidad no debe ser obstáculo para que se mantenga la premisa anterior. Precisamente, cuando la personalidad ha logrado en el hombre su desarrollo más auténtico desde la aparición de la vida, ¿se apartará ahora de su propia ruta estructural? Mucho más lógico es pensar que la hipótesis de un universal-personal, lejos de ser absurda, se comprueba como la más probable y consecuente. Sólo es preciso liberarnos de la (ilusión espacial».

Porque, además, poseemos ya en el campo de nuestra experiencia actual algunos ejemplos limitados que nos muestran la realidad de

20. CYC, 123/ X, 134/. Eșta idea la desarrolla ampliamente en el mencionado ensayo $y$. sobre todo, en La Centrogénesis (AE, 97-127/ VII, 103-134/. 
una personalidad desvinculada de un núcleo particular: el caso de dos amantes cuya unión, lejos de confundirles, los diferencia todavía más. Este ejemplo tiene el valor de un anticipo de lo que puede ser la unión de muchos centros o la totalidad de los centros personales : la propia personalidad se desarrolla más plenamente en el seno de una personalidad común, limitada o universal. Las leyes de la unión nos demuestran que cuando la unificación se realiza (centro a centro», es decir, en lo personal -y sólo entonces- la unión no confunde, sino que diferencia ${ }^{21}$.

La estructura convergente de la evolución nos conduce, pues, a un término (super-consciente), es decir, (super-personal». Al final del proceso de super-humanización no nos espera "Algo", sino Alguien», universal y personal, en quien nuestra propia personalidad se consumará sin confundirse. Teilhard confiesa que su felicidad ("personal) le preocupa poco. Lo que realmente le importa es que su felicidad sea máxima y que (lo mejor de mí mismo se perpetúe para siempre». Pero lo más lógico es pensar que lo que tenemos más (cúnico»y personal se consumará en una realidad de naturaleza personal, en cuyo seno encuentren nuestros (yo) su inmortalización también personal. A un yo corresponde un (tú) o un (él), sin que el (nosotros» sea obstáculo para que se mantenga el (yo» «.

La fe en el Mundo ha tomado ya una (figura) plenamente definida: una Presencia infinitamente amante y amable - puesto que es Personal - nos atrae hacia nuestra plena realización y consumación personal. (Puedo amarla). Y son lógicas nuestras relaciones personales a un nivel humano-reflexivo: una Presencia amorosa "no sería jamás muda). La existencia de una Revelación se nos ofrece como lo más consecuente. $Y$, hasta cierto punto, al menos, se comprende lo razonable que resulta esperar, a partir de nuestra unión personal consumadora en $\mathrm{El}$, una nueva sobre-humanización, gratuita, pero coherente, de nuestra futura super-humanidad natural ${ }^{22}$.

A partir de estas perspectivas, aparece manifiesta la necesidad

\footnotetext{
21. Imposible detenerme más en este punto, que constituye uno de los temas infatigablemente abordados por Teilhard, sobre todo en su última época. Baste recordar el titulado Esbozo de un Universo personalista $(E H, 59-100 / \mathrm{VI}, 67-114)$. Cuando escribia Cómo creo yo, Teilhard carecia todavia de la firmeza y claridad de sus ensayos posteriores a 1936. El tema lo estudio ampliamente en mi tesis doctoral, todavía inédita, La antropología educativa de TC, III parte.

22. CYC, 124-7/ $X, 135-8 /$. Esta idea la desarrolla también en el inédito tantas veces citado Cómo veo yo, n.o 21.
} 
estructural de la religión, esto es, de establecer (rrelaciones personales») con este Foco de amorización y personalización del universo, que posee una Personalidad y, por tanto, un Rostro. Esas relaciones se definen desde el momento en que sabemos que tanto la sobrevida como la super-vida nos espera en la dirección de una conciencia y de un amor crecientes en este Universal-Personal. Es con relación a este Polo que hay que alcanzar - al tiempo que con ello nos realizamos personalmente- como se organiza toda nuestra actividad; es decir, nuestra Moral y nuestra Mística.

En efecto, el Mundo futuro se construye, primordialmente, con fuerzas morales; y la moral, recíprocamente, tiene por función construir el Mundo. Se trata de (una moral de movimiento» que se formula, básicamente, en tres puntos:

- (No es, finalmente, bueno más que lo que contribuye a los aumentos progresivos del Espíritu en la Tierra;

- Es bueno (al menos, fundamental y parcialmente) todo lo que procure un crecimiento espiritual de la Tierra;

-Es, finalmente, lo mejor aquello que asegure su más alto desarrollo a las potencias espirituales de la Tierra).

Tales son los distintivos de la verdadera Moral y de la verdadera Mística : “limitar la fuerza (...) ése es el pecado».

Como es obvio, esta moral y esta mística (de movimiento», se construye sobre el futuro, y se constituye en "persecución de un Dios", en quien, a su vez, subsiste. Al mismo tiempo, por su medio se vehiculiza «la función espiritual de Dios», en la prolongación evolutiva de todas las fibras del Mundo en movimiento ${ }^{23}$.

La religión, por tanto, adquiere un carácter primordialmente activador del esfuerzo humano, a través de una mística cuyos objetivos primarios no pueden ser otros que el desarrollar el sentido céntrico, es decir, la totalización y el personalismo:

"Las fuerzas religiosas emergen de la tremenda prueba que acaban de atravesar como un coadyuvante más esencial que nunca para la filogénesis humana, puesto que, finalmente, a ellas incumbe, en tanto que 'nodrizas de nuestra Fe', en adelante, la misión de mantener y desarrollar la Energía necesaria, requerida por las necesidades, recientemente reconocidas, de una 
Antropogénesis en pleno desarrollo; el ardor de creer, el Gusto por el Mundo" ${ }^{24}$.

Teilhard piensa que si el sentido religioso es una constante humana, lo normal es que (las reservas de Fe», esto es, la cantidad y calidad de sentido religoso disponible, (tienen que crecer continuamente en nuestro mundo", pero adaptadas a las exigencias profundas de la cosmogénesis. En este sentido es claro que lejos de estar superada la Era de la Religión - (no digo de las religiones)-, en realidad está empezando ahora. Pero con una condición esencial:

"que los creyentes se incorporen y salven las nuevas necesidades religiosas de la Tierra. Hasta ahora, las ' $\mathrm{Fe}$ ' eran esencialmente ascensionales. A partir de ahora tienen que ser también motrices (propulsoras)".

La crisis de ateísmo creciente que padecemos se nos revela, en un análisis más profundo, como una crisis de "teísmo insatisfecho", ya que (nuestra necesidad de adorar) no encuentra el cauce institucional adecuado ${ }^{25}$.

c) Un ecumenismo de base (convergencia de las religiones en un credo comin.

Por la lógica misma del crecimiento hemos llegado, por encima de la dimensión individual, a descubrir (la experiencia: religiosa general de la Humanidad». Nada tan equivocado como pensar que la religión es un asunto particular (privado) o que refleja un estadio primitivo y transitorio, propio de la infancia de la humanidad. El fenómeno religioso se nos ha mostrado como (una de las caras de la hominización', ya que, fundamentalmente, consiste en "la reacción, en el Universo en cuanto tal, de la conciencia y de la acción humana colectivas en vías de desarrollo). Por ello, significa mucho más que un asunto privado: afecta a la humanidad entera.

De hecho, sólo tenemos que asomarnos a la historia pasada y presente para que nos encontremos con el "enorme río de las Religiones", En su inmensa variedad de doctrinas y normas morales, sólo algunos rasgos fundamentales permanecen comunes. A primera vista la $1 \mathrm{~m}$ -

24. AE, 223/ VII, 247/ x. Cfr. tb. CC. 121-6/. IX, 131-6/.

25. AE, 223-4/ VII, 248/. Cfr. tb. PH, 321-332/ V, 337-350.

Es el tema estudiado en $\mathrm{mi}$ trabajo precedente. Cfr. asterisco inicial, 
presión no puede ser más descorazonadora. Pero, en una segunda aproximación, comprendemos que la savia religiosa se ha desarrollado y difundido a la manera de un (filum» biológico, como era lógico suponer. Todas ellas, en grado diverso, reflejan la Revelación primitiva y natural en su diálogo concreto con la Presencia que se nos ha hecho manifiesta en el corazón de la cosmogénesis ${ }^{26}$.

Ahora bien, paralelo al proceso general de convergencia - geográfica y psíquica - de la humanidad ((sentido humano»), se observa, con cierto retraso respecto de él, un proceso general de convergencia en los diversos credos religiosos, que es preciso estimular por todos los medios posibles. La mayoría de las dificultades nacen del simple hecho de que los mencionados "credos》 religiosos actualmente vigentes se formularon (en un tiempo en el que los problemas de totalización y de maduración cósmica no se planteaban).

Por eso se agotaban en una perspectiva individualista y concentraban su esfuerzo en la consecución de un (Más Allá) extraterrestre. Pero las nuevas perspectivas exigen no sólo una religión del individuo y del Cielo, sino también una religión de la humanidad y de la Tierra. Esto es lo que necesitamos como un oxígeno indispensable. Por eso se comprende que «sólo podrán subsistir mañana (...) las corrientes místicas capaces de preparar y presentar un alimento completo a 'nuestra sed de ser', por síntesis de la Fe tradicional en lo de Arriba y de la $\mathrm{Fe}$ de nuestra generación en cierta salida hacia Adelante).

En un primer impulso se podría ceder, tal vez, a la tentación de buscar una $\mathrm{Fe}$ totalmente fresca sobre algún (sentido Evolutivo" o sentido Humano» —-desprendiéndonos de los viejos credos»-, en la que se reagruparía (directamente y 'a novo' toda la potencia religiosa de la Tierra). Pero ello resultaría disparatado por simple ley estructural: toda fe se forma sobre otra fe precedente - aunque transformada-, como todo (filum) se constituye sobre otro que le precedió.

La solución debe consistir, pues, en realizar una convergencia adecuada de las religiones en una religión única y renovada, conforme a las nuevas exigencias y dimensiones evolutivas. Pero, ¿cómo se realizará y conforme a qué criterio? Aquí radica el nudo de la cuestión.

26. CYC, 129-130/ X, 139-140/. 
I. Elección de criterio y prueba de las religiones:

La elección de criterio constituye un primer paso decisivo. En

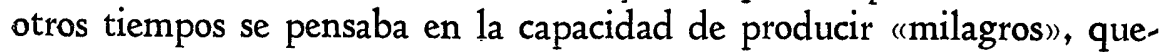
dando en segundo término las directrices propiamente religiosas. Hoy hemos perdido toda confianza en este criterio y nos inclinamos por una (prueba de las religiones) en cuanto a su capacidad de armonía y coherencia con relación a la religión (natural» recién descubierta. En definitiva, se trata de comprobar su valor respectivo sobre la base de su potencial de (excitación evolutiva) hacia los objetivos primarios de la religión natural que la (fe en el Mundo) nos ha descubierto: totalidad y personalismo ${ }^{27}$.

En virtud de este criterio efectuamos ahora las pruebas de las religiones), En primer lugar, caen en bloque los diversos agnosticismos, ya que represan -empirismo social o esteticismo individualla savia que deberían canalizar y propulsar. Tampoco queda nada del grupo islámico, ya que significa un principio de fijación y de estancamiento y sólo puede presentar la imagen de un Dios para beduínos. Por otra parte, su posible rejuvenecimiento le llevaría a una confluencia total con el cristianismo ${ }^{28}$.

Por lo demás, el complejo de religiones que pueden sufrir una confrontación con el (espíritu moderno», se reduce a tres (tipos» de creencias posibles:

\footnotetext{
27. Ib., 131-2/ X, 140-1/; AE, 225-7/ VII, 249-250.

En Lo Crístico, este tema es confirmado con gran fuerza: "En régimen de cosmo-noo-génesis, el valor comparado de los Credos religiosos se mide por su poder respectivo de activación evolutiva" (p. 11), inédito. Toda la cita figura subrayada en el original.

En 1941, a propósito de un Congreso internacional sobre "Ciencia y Religión", en Nueva York, redactó Teilhard unas "observaciones" acerca de las posibles bases de un credo humano común. Se apoya también en su experiencia de treinta años en contacto íntimo con los medios religiosos y científicos de Europa, América y Extremo Oriente. Resume su aportación en tres "bases":

1) El punto actual de divergencia viene dado por un falso dilema entre Dios o el Mundo. De este modo, el potencial religioso de la humanidad se escinde en dos místicas antagónicas, que dilapidan miserablemente "su poder vital de adoración".

2) Un pricipio de convergencia se encuentra en la idea de "Noogénesis". Si nos encontramos en plena génesis del espiritu, se unifican espontáneamente los valores de "personalidad" y "trascendencia"; es decir, las fuerzas propulsivas y las fuerzas ascensionales.

3) El ideal religioso se concreta en "una fe renovada en el progreso humano", superadora de la actual ola de esceptismo en el "gesto sintético de adoración", en el que se unifican y se exaltan mutuamente un deseo apasionado de unirnos a Dios y el esfuerzo apasionado por conquistar el Mundo (construir la super-humanidad), pues ambas metas se implican mutuamente. $\mathrm{PH}$, 98-104/ V, 101-6/.

28. CC, 127-8/ IX, 137-8/. Sin duda Teilhard se muestra algo injusto con el Islamismo. Nótese, sin embargo, que el texto es de 1933. Un año más tarde confirma esta opinión: "Me parece que representa un judaismo residual, $\sin$ personalidad. $Y$ no puede desarrollarse más que haciéndose humanista o cristiano". CYC, 132-3, nuta/ X, 142/.
} 
- grupo de religiones orientales. Su gran seducción se apoya en la proyección eminentemente universalista y cósmica de sus perspectivas. El sentido de la Unidad y del Todo ha dado un impulso incomparable a la vena mística oriental, que tanta fascinación ejerce todavía sobre occidente. Pero su concepto del espíritu es impersonal; más aún, anti-personal. La unídad se persigue mediante la supresión de todo elemento diferencial, que prepara su fusión en el gran Todo. La investigación, el progreso, la realización personal son la peste del alma). La materia es un peso muerto, estéril; todavía más, una ilusión. El camino del espiritu se logra mediante la supresión de lo múltiple. Esta supresión se consigue mediante una pasividad hecha de negatividad. Dios se encuentra en la negación del Mundo.

De la (uruta del Este) sólo puede salvarse, pues, su sentido cósmico y su búsqueda de la unidad. Pero sus procedimientos y directrices se oponen frontalmente al espíritu moderno. Son dos morales, dos metafísicas, dos místicas bajo la misma apariencia monista. Pero c1 equívoco se deshace con su respectiva filosofía de la acción. Por eso la (ruta del Estes) se hace inviable para el hombre moderno. De hecho, asistimos en la actualidad a un "neo-budismo", por contacto con la mística occidental ${ }^{29}$.

Grupo de panteísmos humanitarios. En contraposición a las ve. nerables cosmogonías orientales, las diversas formas de cpanteísmo humanitario) representan brotes novísimos del espíritu religioso. Todas ellas se caracterizan por su escasa codificación (excepto el Marxismo) y por ser religiones sin Dios aparente y sin Revelación. Su raigambre religiosa se manifiesta en su fe contagiosa en un Ideal, al que entregan su vida.

No obstante su gran diversidad de matices, todos coinciden en situar el interés supremo de la existencia en entregarse en cuerpo y alma al Progreso universal, que se les presenta en los desarrollos tangibles de la Humanidad. Hoy asistimos a una (conversión) masiva al nuevo espíritü, cuyos fieles proceden de todos los campos: comunistas y nacionalistas, científicos y políticos, individual y colectiva-

29. CYC 133-4/ $X, 142-3 /$; CC, 128-9\% IX, 138-9. Con frecuencia se ha reprochado a Teilhard su conocimiento convencional de las religiones orientales. A juzgar por lo publicado póstumamente en su obra, habría que convenir en ello. Pero el ensayo inédito, La aportación espiritual del Extremo Oriente (1947) desmiente, en parte, esta apreciación. No obstante, tampoco alli se observa ningún cambio respecto a esta "prueba de las religiones". Lo mismo acontece en otro ensayo inédito: La ruta del Oeste. Hacla una mistica nueva (1932). 
mente. Todos se agrupan en una fe común: “la Religión de la Evolución).

A primera vista, parece existir una coincidencia total entre este neo-humanismo religioso y nuestra (fe en el Mundo». El mismo ardor por construir la Tirra, el mismo sentido cósmico, universalista y futurista; idéntica valoración de la materia y de su potencial espiritual; idéntico entusiasmo por la investigación y la creación; el mismo esfuerzo sin límites para conquistar el tiempo y el espacio.

Pero si profundizamos en el (sentido) dado a su acción y a los objetivos de la misma, se produce una gran decepción. El esfuerzo se realiza con un espíritu (faústico", radicalmente antropocéntrico, sin aspiración trascendente alguna y sin un Omega final, "valorizador») (garantía de irreversibilidad y de inmortalidad) y (amorizador) (personal y personalizante). De hecho, sus esperanzas de super-humanidad carecen de dos factores decisivos: (fe en la Inmortalidad) y "fe en la Personalidad). La ausencia de un Punto Omega resulta desastrosa, incluso para la imagen del mismo hombre (ni inmortal ni personal) ${ }^{30}$.

Teilhard pensaba, sobre todo, en dos formas de "panteísmo humanitarios: el movimiento neo-marxista y el humanismo evolucionista de su amigo J. Huxley. Al primero lo consideraba Teilhard como el más calificado representante de la fe en el "Hacia Adelante)". $\mathrm{Su}$ innegable potencial de contagio y su fuerza los veía Teilhard en su «monopolización (ilegítima del Sentido de lo evolutivo (o sentido humano de la especie) $)^{32}$.

En efecto, para Teilhard el marxismo -refiriéndose, sobre todo, al neomarxismo - no es radicalmente ateo, sino implícitamente religioso. Tal vez en este punto se hiciese Teilhard algunas ilusiones. Pero la repercusión de su pensamiento en los medios comunistas ha venido a confirmar su posición de un diálogo decidido ${ }^{33}$. Lo cierto es que cada vez se hace más patente el acierto de la postura teilhardiana :

\footnotetext{
30. CYC, 134/ X, 143/; CC, 218-9/ IX, 240-1 Cfr .tb. PH, 347-356/ V, 365-374 y el ensayo inédito Cómo veo yo, n.o 36 .

31. PH, 326-8/ V, 343-5/.

32. Carta del 25-IV-1954 (citada por C. Cuénot, op. cit., 515).

33. Asi parece indicarlo el hecho de que sus obras, por primera vez en un pensador cristiano moderno, hayan sido traducidas y hayan encontrado una notable difusión en los paises del Este europeo, incluida Rusia.
} 
“(...) el único modo de vencer al comunismo es presentar a Cristo tal como debe ser: no cual opio (o derivativo), sino como Motor esencial de una Hominización que sólo puede acabarse, energéticamente, en un Mundo abierto por la cima, y amorizado" ${ }^{34}$.

Es decir, realizar una "síntesis del 'Dios' (cristiano) en lo Alto y del 'Dios' (marxista) Hacia Adelante: he aqui al Dios único que ahora podemos adorar 'en espíritu y en verdad" ${ }^{35}$.

En cuanto al humanismo evolucionista huxleyano, Teilhard no podía disimular la simpatía y la coincidencia extraordinaria de opiniones que les unía. Pero se veía obligado a ponerle los mismos reparos que al humanismo neo-marxista: carencia de un Omega final, postulado por la misma estructura convergente de la evolución humana (Objetivo amante y amable), y exigido por su misma centreidad (personal) e irrevisibilidad (inmortal) ${ }^{36}$.

- La corriente cristiana. El gran (filum» cristiano ha inspirado ya las grandes realizaciones de la humanidad durante los últimos veinte siglos y es la única fuerza religiosa que satisface las cuatro vertientes de "la fe en el Mundo". Respecto de las dos últimas, el cristianismo es, por esencia, la religión de lo Inmortal y de lo Personal. Su Dios actúa realmente como Alguien y su cosmovisión culmina en almas inmortales y personales, eternamente responsables de su cometido terrestre.

Sin embargo, las dos primeras - confianza en el Mundo y evolución espiritual - han estado veladas durante siglos en sus perspectivas doctrinales, morales y místicas, oscurecidas por un juridismo extrinsecista decepcionante. No obstante, como hemos visto, al contacto con las nuevas dimensiones evolutivas ha bastado para renovar y rejuvenecer tanto su dogmática implícita como su acción, de tal modo que ol

\footnotetext{
34. Carta del 14/IV/1952 (citada por C. Cuénot, op. cit., ib.).

35. Carta de 1952 (citada ib., 516). Cfr. tb. CYC., 134-5/ X, 143-4. Es la tesis que propropugna en El corazón del problema (1949), PH, 321-332/ V, 337-349/, así como en el ínédito EI Neo-humanismo (1948).

Lo cierto es que el diálogo cristiano-marxista, postulado por Tellhard y aprobado en el Vaticano II, se viene realizando, en gran medida, en torno al propio Teilhard. Cfr. nota 33.

36. Las ideas de J. Huxley se encuentran especialmente en Religion without Revelation (1927, Evolutionary Humanism (1950) y Essays of a Humanist (1964).

Sobre el primer libro comentaba Teilhard: "Aver leí un curioso opúsculo de mi amigo Julian Huxley sobre 'Una Religión sin Revelación', muy sincero y, según mi parecer, verdadero a medias, pero solamente a medias. Evidentemente, el concepto de Revelación debe ser cuidadosamente precisado. Pero la idea de Huxley de que el Hombre puede realizar su organización interna sin una especie de amor cósmico me parece algo imposible y biológicamente ruinoso. EI Hombre no puede más que rebelarse o disolverse, salvo en un 'Mundo amante', que hace falta Jescubrir: una tarea grande y bella". AlH, 245.

Parecida tesis mantiene Lo Crítico, 11-13 (inédito).
} 
cristianismo ha vuelto a encontrarse a si mismo - coherencia internay se ha convertido espontáneamente en (la) religión del progreso universal, con su fe renovada en el (sentido de la Tierra) y en la potencia espiritual de la Materia, así como el sentido de lo humano y de lo cósmico personales ((un Universo personalista)) ${ }^{37}$.

2) No un sincretismo, sino una convergencia de base.

Decidido el criterio y efectuada (la prueba de las religiones», resta todavía decidir el procedimiento según el cual se realizará la lógica y obligada convergencia de las religiones: ¿ ¿será una convergencia entre líneas equivalentes (sincretismo) o sobre un eje privilegiado y central? La solución a elegir es manifiesta, tras el examen de los grandes credos religiosos. Aparte el hecho innegable de ser el único procedimiento acorde con la estructura filética del espíritu religioso : convergencia de base sobre el eje cristiano revitalizado.

En una nota de 1946 plantea Teilhard con su radicalidad característica la problemática del ecumenismo, desbordando ya de entrada los tímidos enfoques habituales. Recoge los reproches que las confesiones cristianas hacen al catolicismo de pretender monopolizar a Cristo en exclusiva, pero subraya también que la historia del ecumenismo es la historia de la desconfianza y de los malentendidos recíprocos. Y es que se parte ya de un planteamiento vicioso: se persigue un ecumenismo estático, por confluencia lateral y mutuas concesiones. Pero el verdadero ecumenismo sólo puede esperarse como un proceso de desarrollo convergente hacia el Cristo Universal, ya que sólo con la Pleromización alcanzará el filum cristiano su plena expansión, interna y externa.

Pero, en realidad, Teilhard se mueve en una óptica mucho más amplia : se trata de conseguir no solamente la convergencia de las diversas confesiones cristianas, sino la de toda la savia que se encierra

\footnotetext{
37. CYC, 136-7/ X, 145-6/; CC, 129-131/ IX, 139-141/.

"Se me ha pedido, y me gustaría realizarlo, una exposición del cristianismo adaptado para la Joven China. Se titularía 'El lugar del Cristianismo en el Universo'. Haría falta mostrar 1.0, cómo la religión responde a una función esencial y continuamente creciente de la Evolución universal; y 2.0, cómo el cristianismo es, de hecho. la única forma actualmente viable de Religión (a pesar, o más exactamente, a causa, justamente, de la parte que hace jugar a la Personalidad y a cierta Revelación". LLZ, 114 (abril de 1930).

Evidentemente, a este proyecto corresponde el ensayo El cristianismo en el Mundo (mayo de 1933), que constituye un primer esbozo de Cómo creo yo. CC, 121-136/ IX, 129-146/.
} 
en las grandes religiones de la tierra y en los humanismos actuales. Por eso, comienza por distinguir dos ámbitos en el ecumenismo.

-ecumenismo de cúspide, exclusivamente entre los cristianos, por explicitación y pleno desarrollo de un cristianismo (ultra-ortodoxo» y "ultra-humano», a escala verdaderamente cósmica. Puesto que se trata de un (filum), sólo es preciso liberarle de las ataduras actuales y potenciarle, en sus diversas vertientes, para que - con su plena expansión interna y externa- se realice la convergencia de un modo espontáneo e irresistible, dentro de un normal pluralismo, como acontece en todo (filum) biológico.

Teóricamente, podrían distinguirse dos procedimientos posibles: convergencia (entre líneas equivalentes) (sincretismo) o convergencia (sobre un eje privilegiado, central), representado indudablemente por la iglesia católica, ya que históricamente le corresponde dicho papel. De hecho, el desarrollo del cristianismo se ha producido a ?a manera de (filum), esto es, como un sistema coherente, progresivo y centralizado. La historia lo comprueba fácilmente. Tras una primera época de difícil desarrollo, el cristianismo alcanzó muy pronto su gran expansión que cristalizó luego en la (cristiandad), al tiempo que de sistema (libre) pasaba a hacerse (comprometido». Esto fue lo que obligó a los diversos cismas y reformas, religiosas y laicas, que se han sucedido desde el renacimiento, en los que ha continuado - aunque de modo indirecto y casi violento - su desarrollo ulterior, mientras el núcleo central - catolicismo- se endurecía más y más, hasta adoptar una actitud de secta, típica de los sistemas indiferentes».

Hoy ha sonado ya el momento de la convergencia de las «ramas) en un frente cristiano, en un concepto de (iglesia viva», en la que debe contarse con un cierto grado de pluralismo dentro del espíritu evangélico común. Por eso se hace tan urgente superar en el seno de las diversas confesiones cristianas -incluído el catolicismola pretensión de constituir un (cuadro") definitivo de verdades inmutables. El desarrollo ecuménico se verificará a la manera de un (filum), por convergencia y mutuo enriquecimiento de las ramas, o no se realizará nunca. Eso sí, la rama católica se ha comportado históricamente como (eje») del despliegue cristiano. Pero también la rama axial precisa de la contribución de las otras ramas laterales y especializadas. Sólo así encontrará su máximo desarrollo. Teilhard ha recalcado con 
energía ambos aspectos. En este sentido, (ser católico es la única manera de ser cristiano plenamente y hasta el fin" ${ }^{38}$.

-Ecumenismo de base, entre todos los credos religiosos y humanistas. Este es el auténtico ecumenismo, que se dirige a "precisar y desarrollar las bases de una fe humana común"), de cara a una exigencia primordial: la gestación de la superhumanidad. A Teilhard le resultaba irrespirable la atmósfera sectaria que descubría en todas las diversas confesiones religiosas y humanistas. Por eso lanzaba decididamente esta consigna:

"Sentir, a la vez y con la misma intensidad, con el Mundo $y$ con la Iglesia. Y ya se sabe en qué sentido digo "Mundo": el inmenso proceso cósmico de ordenación cuya presencia revoluciona, para quien sabe ver, la totalidad de nuestro conocimiento" 39 .

También aquí se enfrentan dos actitudes irreductibles al optar por la dirección sincrética (convergencia de líneas equivalentes) o por la confluencia universal sobre un eje privilegiado y central, que no puede ser otro que el (filum) cristiano, como se deduce de "la prueba de las religiones). Esta es la única solución real, aunque hoy la impida una tupida barrera de prejuicios. Los demás intentos desembocarán siempre en un sincretismo confuso y sin vigor. Por no hablar ya de ciertos intentos ecumenistas a base de sentimentalismo o equívocos concordistas.

Teilhard insiste en que sólo sobre el Dios cristiano, explicitado y enriquecido por las aportaciones convergentes de lo más noble de las savias religiosas y humanas, del presente y del porvenir, es el único centro sólido en torno al cual puede plantearse la empresa de un ecumenismo auténtico: de base y de cúspide.

Intento que hoy, evidentemente, resulta todavía prematuro. En este sentido, se abre ante nosotros una tarea ingente de esfuerzo, apertura y desarrollo. Pero no podemos olvidar que la convergencia

38. Ecumenismo. CC, 228/ IX, 254/; CYC, 184-5/ X, 195-7/.

39. Carta del 14/I/1955, citada por R. d'Ouince, op. cit., I, 186.

La misma idea aparece ya en 1919, en su Nota para la evangelización de los tlempos nuevos: “En los 'Ejercicios' de San Ignacio hay un capitulo 'ad sentiendum cum Matre Ecclesia'/ para sentir con la Madre Iglesia/. Pero recordemos que la Iglesia, para ser una verdadera Madre, debe saber, a su vez, 'sentire cum hominibus'/sentir con los hombres/". ETG, 380. 
sólo es realizable por confluencia hacia adelante, por un proceso dialéctico de autoexpansión, intercambio y decantación ${ }^{40}$.

Concretamente, las religiones orientales pueden aportar su sentido incomparable de la unidad y de la universalidad (sentido cósmico), a la vez que su mística se dinamizará al contacto con la (ruta del Oeste). Los humanismos "panteístas) (marxismo y humanismo evo. lucionista) aportan su magnífica pasión por construir la Tierra y su sentido del esfuerzo autoevolutivo. Por su parte, el cristianismo, eje central de la convergencia - puesto que históricamente es innegable que le compete tal papel $\mathrm{y}$, en definitiva, los humanismos occidentales son desarrollos laterales suyos-, debe aportar el sentido trascendente, inmortalizador y personalizante ((valorizar) y (amorizar) la antropogénesis), con lo que tenemos satisfechas todas las condiciones óptimas para la activación religiosa del proceso de superhumanización ${ }^{41}$.

\section{d) La religión del Cristo-Universal.}

Llegados a esta conclusión de la necesidad de una convergencia general de los credos religiosos y humanistas sobre la base del cristianismo, sólo nos resta precisar con mayor exactitud el papel propio del ("credo) cristiano. Ya hemos visto cómo en la concepción teilhardiana, por estricta exigencia estructural, la convergencia (de base» viene precedida -o englobada al menos- por una convergencia «de cúspide» entre las confesiones cristianas, que han de converger sobre uel eje católico». En el esfuerzo "conjugadò) de ambos ecumenismos nace la esperanza de formular un "credo humano»" ${ }^{42}$.

40. CC, 227-8/ IX, 253-4/; AE, 210-2/ VII, 232-4/; ib., 373-382/ VII, 417-426/; PH, 96-7/

41. CC, 227-8/ IX, 253-4/; ib., 131-5/ IX, 141-5/; ib., 218-9/ IX, 240-1/. Puede verse también el excelente resumen que presenta en su ensayo de 1950 El fenómeno cristiano (CYC, 219230/ $X, 231-243$ ). La misma tesis se expone en ib., 85-103/ X, 93-113/; FH, 353-361/ I, 324-332/; $E H, 97-100 / 1,324-332 /$; $E H, 97-100$ / VI, 110-114/; ib., 169-173/ VI, 192-8/.

Sin embargo, hay que tener en cuenta la advertencia del propio Teilhard: "¿Por qué me atribuyen la idea de que el espíritu evolucionaría 'naturalmente', por asi decir, hacia el orden sobrenatural? /.../ Cuando hablo de convergencia de religiones, el contexto prueba sobreabundantemente que, en mi pensamiento, esta convergencia debe hacerse sobre el eje cristiano, encontrando los otros Credos en la fe en Cristo la expresión justa de lo que perseguían sus tanteos hacia la Divinidad". Escrito de 1947, citado por H. de Lubac, op. cit., 210.

Téngase en cuenta, no obstante, también, que este escrito refleja un estado de cierta intimidación, ocasionado por la crítica de Garrigou-Lagrange a propósito de Cómo creo yo.

42. CC, 228/ IX, 254/.

En septiembre de 1931 escribia: "El mensaje esencial de Cristo va contenido por entero en el anuncio de una Paternidad divina. Traduzcamos: en la afirmación de que Dios, Ser personal, 
La verdad es que Teilhard rehuye siempre exponer los términos precisos de esta convergencia de cúspide». Pero ha dejado bien claro, sobre todo a partir de 1948, que, pese a sus defectos y decepciones, el catolicismo actúa como (eje) central, en cuanto es "Iglesia viva», de la que toma su savia la Iglesia docente y jerárquica.

Esperar o desear otro tipo de ecumenismo que no sea de "cúspide» entre los cristianos sería ilusorio y, además, injusto. Porque, ya lo hemos visto, la Revelación continúa, y no sólo de un modo extrínseco, sino desde dentro, evolutivamente. Aquí radica una de los obstáculos más urgentes a superar:

"La idea de investigación religiosa no se abre paso a causa de una falsa idea de Revelación (...) Se sigue considerando la verda a como cerrada, cercada, no como convergente. El catolicismo es el eje principal, pero todavía no ha alcanzado su término axial. Hay líneas oblicuas que lo enriquecen. Sin el catolicismo, con su fletismo un poco endurecido, los protestantismos se hubieran desvanecido enteramente. El eje los ha seguido sosteniendo. Ellos trabajan mucho más la tradición con lo humano. Se han separado, pero funcionan en un conjunto. Este es el verdadero ecumenismo. Han prestado enormes servicios. Han aportado la crítica bíblica" ${ }^{43}$.

Para Teilhard, la mayoría de las disensiones internas de los cristianos han sido productos de su (infidelidad) al mensaje, de sus desviaciones históricas, en ocasiones tan graves que hicieron peligrar su trasmisión esencial y amenazaron convertir las confesiones cristianas en (sectas), como aconteció de hecho con tantas ramas protestantes.

En cambio, este esperado ecumenismo de (cúspide» conduce a una plena explicitación y desarrollo del Cristo Universal. Es lo que Teilhard llamaba (ultra-ortodoxia». En su ámbito, el catolicismo no constituye un cuadro de formulaciones dogmáticas a imponer, sino que se comporta como un «eje» central de desarrollo. Los credos cristianos se comportan como las diversas ramas de un (filum); por eso "funcionan en un conjunto».

\footnotetext{
se presenta al Hombre como término de una unión personal. Ya muchas veces ( $y$, sobre todo, al alborear la era cristiana) el pálpito religioso humano se había aproximado a esta idea de "que Dios-Espíritu sólo era alcanzable por el espiritu. Pero únicamente en el Cristianismo adquiere este movimiento su consistencia definitiva. La entrega del corazón en lugar de la prosternación del cuerpo, la comunión allende el sacrificio, Dios-Amor que no se alcanza, al fín, más que por el Amor: he aquil la revelación psicológica y el secreto del amor cristiano". CV, 215/ LV, 212/.

43. Carta del $7 / \mathrm{VII} / 1954$ a Claude Cuénot, inédita. El subrayado es mío.
} 
La consecuencia es el enriquecimiento y la expansión convergente de todas ellas. Esto se aplica también al catolicismo. Teilhard confiesa cómo le chabía decepcionado, en primera instancia, a causa de sus estrechas representaciones del Mundo, y por su incomprensión del papel de la Materia. Ahora reconozco que, después del Dios encarnado que revela, ya no puede salvarme más que formando cuerpo con el Universos) ${ }^{44}$.

Respecto del ecumenismo de (base), tampoco se trata de imponer la visión cristiana, sobre todo la actualmente vigente, sino que se persigue la mutua fecundación y potenciación, tal como se expresa en "la religión del Cristo Universal), es decir, "la síntesis de Cristo y del Universo).. De hecho, es manifiesto cómo la nueva savia de los humanismos contemporáneos -que, en última instancia, no lo olvidemos, proceden del tronco cristiano- ha actuado providencialmente para revitalizar a un cristianismo anquilosado y casi sectario, a la vez que el Dios cristiano confiere al esfuerzo evolutivo de sentido pleno (valorización y amorización) ${ }^{45}$.

Eso sí, el (ceje) cristiano ocupa en el conjunto una posición central. Es la tesis que defiende con toda claridad en Cómo veo yo:

"En el Universo, según hemos reconocido antes, la Vida es el fenómeno central; y, en la Vida, el Pensamiento; y, en el Pensamiento, la ordenación colectiva de todos los pensamientos sobre sí mismos. He aquí que ahora, por una cuarta opción, nos vemos conducidos a reconocer, todavía a mayor profundidad, es decir, en el corazón mismo del fenómeno social, una especie de ultra-socialización en curso, gracias a la cual 'la Iglesia' se forma poco a poco, vivificando por su influencia y recogiendo bajo su forma más sublime, todas las energías espirituales de la Noosfera. La Iglesia, porción reflexivamente cristificada del Mundo; la Iglesia, foco principal de afinidades interhumanas por super-ca-

\footnotetext{
44. CYC, $137-140 / X, 146-9 /$.

Por lo demás, Teilhard conocía muy deficientemente los desarrollos concretos y la evolución de las diversas confesiones cristianas, fuera del catolicismo.

45. Véanse estas explicitaciones:

"Mientras el Universo era considerado como un sistema estático, es decir, en la práctica, de trama genéticamente amorfa, el advenimiento del Reino de Dios en él no presentaba ninguna dificultad estructural. En efecto, no había que ajustar sobre el Verbo encarnado (...) los rumbos plásticos del destino humano". Cómo veo yo, 25x (inédito).

"Las formas aún vivientes del teísmo (comenzando por la cristiana) tienden a des-humanizarnos en la atmósfera rarificada de un cielo demasiado alto. Sistemáticamente cerradas todavía a los grandes horizontes y a las grandes corrientes de la cosmogénesis, no sienten verdaderamente con la Tierra; una Tierra cuyos roces internos pueden suavizar aún, como un lubrificante bienhechor, pero no pueden animar sus resortes, como sería necesario". Lo Cristico, 13 (inédito).
} 
ridad (...); la Iglesia, eje central de convergencia universal y punto preciso del encuentro fulgurante entre el Universo y el Omega" ${ }^{46}$.

Precisamente, esta es la función específica del (fenómeno cristiano', como expone Teilhard en el mismo opúsculo. No se trata de una afirmación gratuita, sentimental o sectaria, sino de una constatación de orden (experimental): la existencia (en el seno de la Humani$\mathrm{dad}$, de una corriente religiosa caracterizada por el siguiente grupo de cualidades: intensa vitalidad; prodigiosa 'adaptividad' que, contrariamente a las otras religiones, le permite desarrollarse al máximo, principalmente en la zona misma de crecimiento (en el 'meristemo', como diría un botánico) de la Noosfera; finalmente, una semejanza muy notable en sus perspectivas dogmáticas (convergencia del Universo sobre un Dios subsistente y super-personal) con todo lo que nos enseña el estudio del Fenómeno Humano».

Esta situación puede pasar inadvertida, pero «un ojo sensibilizado") puede descubrir desde una sospecha a una certeza: representa (la revelación de Omega), de un modo "afectivo e inteligible», sobre (la cara refleja de la Noosfera). Todo nos empuja a una adhesión (dialéctica), un (acto de fe") vital. Al menos, contamos con el criterio de coherencia y activación: todo se esclarece y se precisa en la estructura y en la marcha general del Universo ${ }^{47}$.

Pero no olvidemos que para ello es preciso que se produzca cel rebote cristiano de la evolución al mismo tiempo que el rebote humano del cristianismo. Por fidelidad a la teología de la Encarnación, sabemos que no se da ninguna clase de (independencia, sino una subordinación coherente, entre la génesis de la Humanidad en el Mundo y la génesis de Cristo, por su Iglesia, en la Humanidad. Inevitablemente, por estructura, los dos procesos están vinculados» ${ }^{48}$.

e) (las sombras de la fe).

No obstante las seguridades que le proporcionan los criterios

\footnotetext{
46. Cómo veo yo, 2 n.o 24. Es la tesis que expone también en el ensayo ¿Agitación o génesis (1947). $P H, 261-278 / V, 273-289 /$.

"El Cristianismo, ¿no es una Religión? Si, en el sentido de que es el alma de la Evolución, $y$ de todas las religiones' (...), es la Religión (el eje de las religiones) que se forma gradualmente por depuración de todas las otras". Carta a Combaluzier, 21/XII/1949, inédita.

47. Cómo veo yo, n.o 22. Cfr. CC, 197-9/ IX, 216-8/; CYC, 141-2/ X, 149-150/.

Puede verse la magnífica exposición que hace de estos temas Ch. Mooney, op. cit., 154-168
} 
conjugados de coherencia y de activación, Teilhard cierra sus (confesiones) con un epílogo sorprendente, aunque, por otra parte, perfectamente lógico: "las sombras de la fe». Es la confesión de su duda y la resolución de una búsqueda incensante sobre el contenido de la revelación. En otras palabras, es la advertencia sobre la necesaria provisionalidad de toda reformulación y el propósito de esfuerzo continuado de renovación y trasposición del mensaje cristiano.

Engañados por la apariencia exclusivamente biográfica del escrito, los comentaristas no le han concedido la atención necesaria a este epílogo. Pero, en realidad, constituye un quinto punto estructural en su visión del "cristianisme del futuro». Sus investigaciones y sus dudas, su constante esfuerzo para conseguir una explicitación más adecuada de sus propios resultados, marcan también una línea a seguir para todo pensador cristiano.

Su cosmovisión no significa, pues, un sistema de verdades definitivas. $\mathrm{Ni}$ a él ni a ningún otro le ha sido concedida la clarividencia final. Nada nos ha sido dado definitivamente. La revelación no sig. nifica el regalo de un contenido dogmático de una vez para siempre. La visión es casi tan oscura para quien tiene datos revelados como para quien no los tiene. Sigue siendo incierta, titubeante. También los creyentes buscan en la oscuridad. La revelación les proporciona solamente - ¡ aunque signifique tanto! - la orientación de su búsqueda. Pero no les dispensa de una auténtica y rigurosa investigación, incesantemente mantenida ${ }^{49}$.

Porque, además, ya lo hemos visto: la revelación continúa. El teólogo ha de procurar captar el mensaje en el seno de las situaciones cambiantes. $\mathrm{La}$ ("verdad definitiva) no está a nuestro alcance. Ocurrirá solamente al final de los tiempos. Ahora perseguimos $-y$ nos basta - la aptitud de nuestra imagen del mensaje cristiano para reflejar la verdad evangélica, hacer comprensible y eficaz su contenido salvador. No es una proclamación de relativismo generalizado, sino la exigencia ineludible de nuestra historicidad. La verdad absoluta existe. Pero no somos dioses. Conocer la verdad absoluta rebasa nuestra capa-

\footnotetext{
48. $\mathrm{PH}, 49-52 / \mathrm{V}, 50-3 /$.

49. Pueden verse en la obra de B. de Solages, 351-4, multitud de testimonios sobre la "provisionalidad" constante de su visión.
} 
cidad. Sólo podemos realizar un progresivo acercamiento --histórico y situacional-a ella.

Como dice Teilhard, "creer no es ver), sino (marchar entre las sombras de la fe). Se ha querido interpretar estas expresiones en un simple contexto de ascética, cuando, en realidad, expresan el imperativo de nuestra condición de "peregrinos del Reino». Como hace observar Teilhard, "somos aún incapaces» de más luz ${ }_{+}$dado nuestro actual estadio evolutivo. A lo largo de los siglos nuestros ojos se han abierto incesantemente a la luz y así hemos de continuar hasta la Pleromización final. En estas condiciones, no importa que los horizontes "se encuentren velados por la bruma». Sabemos que, al final de nuestra honrada búsqueda, la Verdad nos espera ${ }^{50}$.

Su último escrito importante, Lo Cristico, parece cerrarse con un grito triunfal y profético: iTierra prometida!». Pero refleja, en realidad, una postura similar. Por un momento sueña con una cexplosión” de luz que alcanzara a toda la Noosfera. Pero, en definitiva. sabe que se trata de un intento limitado; tal vez sólo una primera aproximación.

Por un momento también parece vacilar: "¿sólo yo he visto?" De hecho, ¿por qué me siento tan iquieto, tan incapaz de expresarme, de comunicar la maravillosa "diafanía?) Tal vez sea simplemente víctima de un reflejo interior: "es lo que me pregunto frecuentemente».

Pero le sostiene una triple evidencia: coherencia profunda, poder contagioso, superioridad indudable de su visión. Ciertamente, se

50. CYC, 143-5/X, 151-2. El sentido teilhardiano de revelación. Lo estudio en otro capítulo del libro. Baste aqui uria referencia adicional de 1919: "Se nos ha habituado a considerar la Revelación como un esplendor que ilumina distintamente toda la estructura del mundo. Para no hacer sonreir a los Gentiles(...) es urgente que llevemos a su justa proporción los dones que Dios nos ha hecho en la Escritura. La verdad divina no es todavia para nosotros un sol, sino solamente una estrella encendida en medio de la noche. Por Jesucristo y los profetas sabemos en qué sentido, hacia qué término se mueve el (centro) núcleo de nuestra pequeñez. Pero sobre los prolongamientos del Mundo, y de nuestra persona, sobre las fases históricas y las condiciones físicas de nuestro retorno a Dios, nosotros no sabemos casi nada. Nos movemos en las tínleblas hacia un punto luminoso; $y$, si no defendemos encarnizadamente nuestra visión, si no la reconquistamos a cada instante, la vista misma de la estrella se nos escapará. He ahí la bellisima realidad. Quien quiera continuar viendo debe luchar a cada instante por la luz. El cristiano nó escapáa a esta ley noble y austera que liga conjuntamente al espíritu y a la verdad.

Por eso, una Iglesia que, por imposible, no buscase en cada instante a su Dios como si -pu diese perderlo (iba a decir, como si no lo tuviese todavia) sería una Iglesia muerta, rápidamente disueita en medio del pensamiento humano". ETG, 376-7. 
ro azar. Pero la cadena continuará: basta que aparezca la Verdad (una sola vez, en un sólo espíritu, para que nada pueda ya, jamás. impedir que lo invada y lo inflame todos ${ }^{51}$.

\section{JOSE RuBro}

51. Lo Cristico, 13-14 (inédito).

* "Incredulidad moderna y cristianismo en Teilhard de Chardin". ESTUDIO AGUSTINIANO VI, fasc. II, pp. 215-237

Advierto al lector que este trabajo constituye el capitulo final de un libro titulado La trasposición del cristianismo en Teilhard de Chardin, que aparecerá próximamente.

Utilizo las siglas siguientes:

CYC: Como yo creo. Taurus, Madrid 1970.

$\mathrm{X}$ : Comment je crois. Seuil, Paris 1969.

ETG: Escritos del tiempo de la guerra. Taurus, 2. ${ }^{\text {a }}$ ed., Madrid 1967 Ecrits du temps de la guerre. Grasset, Paris 1965.

CC: Ciencia $y$ Cristo. Taurus, Madrid 1968.

IX: Science et Christ. Seuil, Paris 1965.

AE: La activación de la energia. Taurus, 2. ${ }^{a}$ ed., Madrid 1967.

VII: L'activation de l'énergie. Seuil, Paris 1963.

CV: Cartas de viaje. Taurus, $4 .^{2}$ ed., Madrid 1966.

LV: Lettres de voyage. 1923-1955. Grasset. Paris 1956.

EH: La energía humana. Taurus, 2. ${ }^{a}$ ed., Madrid 1967.

VI: L'énergie humaine. Seuil, Paris 1962.

PH: El porvenir del hombre. Taurus, 4. ${ }^{\text {a }}$ ed., Madrid 1967.

V: L'avenir de l'homme. Seuil, Paris 1959.

FH: El fenómeno humano. Taurus, 4. ${ }^{a}$ ed., Madrid 1967.

I: Le phénomène humain. Seuil, Paris 1955.

AIT: Accomplir l'Homme. Grasset, Paris 1968.

LLZ: Lettres é Leontine Tanta. Desclée de Brouwer. Paris 1965. 